\title{
APPLICANT ATTRACTION STRATEGIES: AN ORGANIZATIONAL PERSPECTIVE
}

Sara L. Rynes

Cornell University

Alison E. Barber

University of Wisconsin

Working Paper \#89-14

May 1989

Center for Advanced Human Resource Studies

New York State School of Industrial \& Labor Relations

Comell University

Ithaca, N.Y. 14851-0952

(607) $255-2740$

DRAFT: NOT TO BE DUPLICATED OR CITED WITHOUT AUTHORS' PERMISSION

This paper has not undergone formal review or approval of the faculty of the ILR School. It is intended to make the results of Center research, conferences, and projects available to others interested in human resource management in preliminary form to encourage discussion and suggestions. 


\begin{abstract}
Developing labor shortages are expected to increase the importance of applicant attraction into the next century. Unfortunately, previous research has provided little in the way of unified theory or operational guidelines for organizations confronted with attraction difficulties. In part, this is because much research has been framed from the applicant's, rather than the organization's, perspective. In addition, attraction-related theories and research are scattered across a variety of literatures, and often identified primarily with topics other than attraction per se (e.g., wage, motivation, or discrimination theories).

The present paper draws on multiple literatures to develop a model of applicant attraction from the organization's perspective. In it, we (1) outline three general strategies for enhancing applicant attraction, (2) propose broad categories of contingency factors expected to affect the choice (and potential effectiveness) of alternative strategies, (3) suggest probable interrelationships among the strategies, (4) link applicant attraction strategies to other human resource practices, (5) outline various dimensions of attraction outcomes (e.g. qualitative and quantitative, attitudinal and behavioral, temporal), and (6) discuss implications for future attraction research.
\end{abstract}


Introduction

Organizations have always been concerned about attracting and selecting the "right types" of employees (e.g., Schneider, 1976 \& 1987). However, the relative attention paid to attracting, versus screening, new employees depends on many factors such as the relative attractiveness of the vacancy and the general state of the labor market (Guion, 1976; Rynes, in press).

In the latter regard, demographic developments such as the baby bust and the leveling off of female labor force participation rates suggest that widespread labor shortages will develop and persist well into the twenty-first century. Along with these trends, demographers predict an increased emphasis on labor attraction (Johnston, 1987). Indeed, increased concerns about applicant attraction are already apparent in the popular press (e.g., Bernstein, 1987; Finney, 1989; Hanigan, 1987; Merrill, 1987).

To date, the management and organizational behavior literatures have focused on recruitment as the dominant tool for attracting applicants (Rynes, Heneman \& Schwab, 1980; Schwab, 1982; Wanous, 1980). However, prior economic research into the functioning of labor markets suggests that improved recruitment is frequently an inadequate response to attraction difficulties, particularly when vacancies are unattractive, or labor shortages persistent (e.g., Kerr \& Fisher, 1950; Malm, 1955; Doeringer \& Piore, 1971). In such situations, more aggressive strategies generally become necessary.

In light of these considerations, the present paper draws from multiple literatures (economics, human resource management, industrial psychology, organizational behavior, and sociology) to develop an interdisciplinary model of applicant attraction. Moreover, unlike most psychological treatments of applicant attraction (e.g, Rynes, et al., 1980; Wanous, 1977), the present model is developed from the organization's rather than the applicant's perspective.

Anticipated benefits of adopting an interdisciplinary, organizational perspective include the following: (1) discussion of a broader range of strategies for attracting applicants; (2) delineation 
of contingency factors affecting strategic choices, (3) consideration of potential interrelationships among altemative strategies; (4) increased awareness of potential differences in organizational responses to diverse environmental conditions; (5) a series of testable propositions regarding the conditions under which various strategies or combinations of strategies will be employed, (6) greater awareness of the interrelationships between attraction strategies and other human resource practices, (7) consideration of a broader range of attraction-related outcomes, and (8) suggestions for making future attraction research more relevant to organizational decision makers.

\section{Domain and Boundaries}

At the outset, it is helpful to delineate the boundaries of the present discussion. First, the model focuses primarily on applicant attraction, as distinct from screening or selection. Although attraction and selection are inherently intertwined in the process of filling vacancies (e.g., Boudreau \& Rynes, 1985; Schwab, 1982), we focus here on activities designed to increase the number, or change the characteristics of, individuals willing to consider joining an organization.

Second, the model makes a distinction between "attraction" and "recruitment". Although recruitment theories often treat recruitment as largely synonymous with attraction (e.g., Rynes, et al., 1980; Schwab, 1982), the present paper views recruitment as a means of accomplishing applicant attraction. Thus, improved recruitment is regarded as one potential strategy for enhancing attraction, but so are decisions to modify employment inducements or to target different kinds of applicants.

Third, the model is concemed primarily with strategic choices in novel or changed situations (e.g., precipitous decline in labor supply; new job creation). Under normal conditions. organizational decision makers follow largely automatic scripts involving little conscious decision making or "strategic" choice (e.g., Klein, 1989; Osterman, 1987). However, when conventional scripts fail to produce desired results, decision makers begin to consciously seek new, more 
effective strategies. We attempt here to delineate the factors affecting the choice, and likely effectiveness, of various strategic options.

\section{The Model}

The present model outlines three conceptually distinct (albeit often interrelated) strategies for attracting applicants: (1) altering recruitment practices, (2) targeting nontraditional applicants, and (3) modifying employment inducements (Figure 1). Although psychological research has primarily emphasized recruitment strategies, economic and sociological field research has demonstrated that inducement and applicant targeting strategies also play an integral role in attempts to attract more, better, or more cost-effective applicants.

Insert Figure 1 about here

As shown in Figure 1, a number of contingencies are hypothesized to influence the relative mix of the three strategies. These include labor market conditions (e.g., expected duration of labor shortages), vacancy characteristics (e.g., relative attractiveness), organizational constraints (e.g., ability to pay), and phase of the attraction process (e.g., job application versus job acceptance).

Additionally the model suggests that when conscious decision processes come into play, altemative strategies are generally considered interactively rather than independently (e.g., see Doeringer \& Piore, 1971). Thus, for example, decisions about applicant pools and recruitment messages are based at least in part on decisions about employment inducements.

The model also suggests several ways in which attraction strategies interact with other human resource (HR) management practices. More specifically, attraction strategies both affect, and are affected by, current HR practices. For example, the adoption of new inducement strategies is frequently constrained by current compensation practices. Conversely, decisions to target new applicant pools often necessitate changes in selection methods (Doeringer \& Piore, 
1971; Osterman, 1987), as well as post-hire practices (e.g., socialization and training; see Fisher, 1986; Sutton \& Louis, 1987).

The model also emphasizes the multidimensionality of attraction outcomes. For example, outcomes have both quantitative (e.g., number of applicants, job acceptance rates) and qualitative dimensions (e.g., acquired skills, aptitudes, direct costs and cost-effectiveness of acceptees). Additionally, there are multiple phases to the attraction process, each with its own unique outcomes. For example, an organization may get many applications but few acceptances, or insufficient applications but high acceptance rates. Finally, attraction processes generate both attitudinal (e.g., perceived organizational image) and behavioral (e.g., job rejection) outcomes.

Finally, the model incorporates previous theory and research suggesting that attraction strategies influence post-hire outcomes. For example, psychologically-oriented research has linked variations in recruitment sources or realistic previews to newcomer satisfaction and length of service (e.g., Breaugh, 1981; Wanous, 1980). The present paper extends this discussion to other attraction practices (e.g., inducements) and outcomes (e.g., "insider" attitudes and behaviors) as well.

\section{General Attraction Strategies}

Under any given set of market conditions, at least three conceptually distinct strategies exist for increasing success in attracting labor. These are: (1) improving recruitment practices, (2) altering employment inducements, and (3) targeting nontraditional applicants. Each is discussed in turn.

\section{Recruitment Practices}

Of the proposed attraction strategies, recruitment practices have received the most attention in the management and organizational behavior literatures. The present paper briefly summarizes four dimensions of recruitment that have been hypothesized to influence applicant attraction. 
Organizational Representatives. Several characteristics of organizational representatives (e.g., recruiters, hiring managers) have been hypothesized to affect applicants' impressions and decisions about organizations. If in fact organizational representatives have important effects on applicants, it would make sense to ensure that recruiting representatives possess the "right" characteristics through selection, training, or some combination of the two (Rynes \& Boudreau, 1986).

To date, research on organizational representatives has concentrated almost exclusively on campus recruiters. A review of this research suggests that: (1) recruiter characteristics explain more variance in attitudes that are far removed from job choice (e.g., impressions of recruiters per se) than those closer to choice (e.g., likelihood of accepting a job offer); (2) recruiter characteristics generally explain less variance in studies that control for job characteristics than those that do not, and (3) virtually no evidence exists that actual job choices are affected by recruiters, once job characteristics are taken into account (Rynes, in press).

Thus, the employer wishing to attract more or better applicants will not find much support for the notion that improving the performance of organizational representatives will enhance job acceptance rates (although it may enhance the more general "public relations" aspects of attraction). It should be noted, however, that prior research has not directly tested the potential benefits of recruiter selection and training programs. Rather, recruiters have been studied as "naturally occurring phenomena" in campus placement offices. Second, it should be noted that other (unstudied) representatives such as hiring managers or potential coworkers may exert greater influence on applicants than do campus recruiters (e.g., Fisher, Ilgen \& Hoyer, 1979).

Recruitment Messages. A second recruitment dimension that may affect attraction is the nature of the "message" transmitted to prospective employees. Although vacancies are ostensibly composed of a "given" set of attributes, discretion is nevertheless possible in terms of the content, favorability, and detail with which vacancies are described. Room for discretion 
arises from such factors as imperfect job seeker information, inherent subjectivity in describing and evaluating certain attributes (e.g., career prospects), and the flexibility built into many job descriptions (Schwab, et al., 1987).

To date, the vast majority of research has focused on message favorability (usually called "realism"), rather than on message content or level of detail. Interest in message favorability arose from concerns that employers take advantage of job seeker uncertainty to "oversell" vacancies (e.g., Schneider, 1976), perhaps at the expense of subsequent employee satisfaction and turnover.

Empirical evidence is mixed as to whether or not realistic messages reduce job acceptance rates. For example, a meta-analysis of ten studies showed no effect whatsoever $(d=.00)$ until a large outlier containing more than $1 / 4$ of the total sample was eliminated from the analysis (Premack \& Wanous, 1986). Additionally, considerable work remains to identify the psychological processes involved, the generalizability of effects across a wide variety of jobs and applicants, and the productivity-related characteristics of acceptors versus rejectors under more (less) favorable messages (Rynes, in press).

Beyond favorability, however, other potentially important message dimensions remain almost completely unstudied. These include (1) the effects of emphasizing certain kinds of content over others (e.g., extrinsic versus intrinsic, verifiable versus nonverifiable); (2) the effects of revealing various kinds of information (e.g., pay) at early versus late stages of the process; (3) the most effective ways to present credible information about nonverifiable attributes; (4) the extent to which strategies for designing effective recruitment messages generalize across "good" and "bad" jobs', and (5) whether different kinds of information (e.g., verifiable and nonverifiable) are equally effectively communicated across different media.

Recruitment Sources. Success in attracting desirable employees may also depend upon the source(s) through which applicants are located. Presumably, sources differ in the extent to 
which they provide detailed and accurate information (both to applicants and employers), as well as in the productivity-related characteristics of the applicants reached (e.g., Ullman, 1966; Schwab, 1982).

To date, research on recruitment sources has focused exclusively on (1) selectees rather than job applicants and (2) post-hire rather than pre-hire outcomes (e.g., Breaugh, 1981; Taylor \& Schmidt, 1983). Unfortunately, selection, self-selection, and post-hire effects are all inherently confounded in such research (Rynes, in press). As such, extant research has little to say about source effects on applicants' pre-hire attitudes, productivity-related characteristics, and decisions.

Recruitment Timing. Two hypotheses have been offered as to how recruitment timing might be modified to an employer's advantage. The first suggests that by avoiding delays between recruitment stages, employers can minimize the chances of discouraging applicants and causing them to accept other offers (Rynes, et al., 1980). To date, this hypothesis has received little empirical attention, and only mixed support (see, e.g., Arvey, Gordon, Massengill \& Mussio, 1975 versus Taylor \& Bergmann, 1987).

The second hypothesis suggests that employers who extend the first offer to a candidate may have an advantage over those who extend subsequent offers. According to Soelberg (1967), the costs, anxieties and uncertainties of job search cause many applicants to favor "sure" offers over uncertain ones, provided they do not contain any minimally unacceptable features (e.g., insufficient salary). If true, employers who practice early recruitment may have a competitive advantage in attracting applicants. However, this strategy may only work for employers of above-average competitiveness, as the "best" applicants (see footnote 1) may not jump at early offers unless those who offer them are also highly desirable employers (e.g., Weiss, 1980; Yellen, 1984). 
In sum, despite the fact that the timing of recruitment activities has been hypothesized to affect both the quantity and quality of applicants attracted, no firm conclusions can be drawn about timing effects.

\section{Employment Inducements}

A second strategy for enhancing applicant attraction is to improve the nature of the inducements offered. For example, employers who are confronted with attraction difficulties can raise salaries, improve benefits, implement flextime, provide child or eldercare, develop internal career paths, or make any number of other improvements in working conditions. Although previous studies have typically used the term "job attributes," we use the term "inducements" to convey the notion of deliberately modifying attributes for the explicit purpose of enhancing job attractiveness.

Most research on employment inducements has been of limited usefulness to organizations. For example, the vast number of attribute rating or ranking studies share a number of serious flaws that threaten both their intemal and external validity (e.g., Lawler, 1971; Rynes, Schwab \& Heneman, 1983). Policy capturing experiments address some of these difficulties (e.g., they reduce social desirability tendencies and provide a concrete decision context), but introduce limitations of their own. For example, policy capturing experiments involve hypothetical rather than real job choices, cannot be generalized beyond the inducements and inducement levels presented, and presume market characteristics that are not realistic for most job seekers (e.g., perfect information, multiple simultaneously available alternatives; Schwab et al., 1987).

Nevertheless, previous research does suggest that job attributes are far and away the major determinants of applicant reactions. For example, in the few psychological studies that have simultaneously examined recruiters and job attributes, both laboratory experiments and field surveys suggest that attributes dominate applicants' attitudes, particularly at later stages of the attraction process. In fact, recruiter effects have typically faded to nonsignificance once job 
attributes are taken into account (e.g., Powell, 1984; Rynes \& Miller, 1983; Taylor \& Bergmann, 1987; for an exception see Harris \& Fink, 1987).

Moreover, a limited number of field experiments suggest that inducements affect behaviors as well as attitudes, and applicant quality as well as quantity. For example, experimental inducement programs in the Armed Services have shown that both the quantity and quality (as measured by aptitude test scores) of Army recruits are highly sensitive to changes in extrinsic inducements such as salaries, recruitment and retention bonuses, and educational incentives (e.g., Lakhani, 1988; Tannen, 1987). Similar results were obtained in a cross-sectional examination of Navy enlistment rates by region, where enlistments were modeled as a function of alternative employment opportunities, regional office expenditures on recruitment, and Naval salaries relative to local wage levels (Hanssens \& Levien, 1983).

Unfortunately, a variety of difficulties prohibit firm conclusions as to precisely which inducements are most strongly related to applicant attraction. For example, different methodologies appear to produce different attribute preference hierarchies (Schwab, et al., 1987). In addition, the relative importance of various inducements appears to be subject to both individual differences and differences in market characteristics (Lawler, 1970; Reynolds, 1951). Still, theoretical arguments (e.g., Rottenberg, 1956; Schwab, et al., 1987) and limited empirical research (e.g., Lakhani, 1988; Rynes, et al., 1983; Tannen, 1987) suggest that verifiable attributes with calculable pecuniary value are likely to be particularly effective attractors. Applicant Pools

A third way to increase the ability to attract labor is to direct recruitment efforts toward individuals who are, for one reason or another, less marketable than "traditional" applicants or the applicants sought by competitors (e.g., Finney, 1989). Generally speaking, organizations are assumed to target initial recruitment activities toward the most desirable individuals they think they can attract (e.g., Kerr \& Fisher, 1950; Malm, 1955; Doeringer \& Piore, 1971). 
However, if such efforts fail, they are then hypothesized to relax their standards until all vacancies are filled (Thurow, 1975).

Considerable empirical evidence supports these assumptions. For example, during World War II, employers sought women and handicapped applicants for jobs formerly filled only by able-bodied males (Kerr \& Fisher, 1950). More recently, employers turned to untrained clerical and administrative employees to fill entry-level programming jobs when programmers became scarce and expensive (Osterman, 1987).

Although targeting nontraditional applicants might, at first glance, be assumed to lead to lower subsequent productivity and overall utility, it should be noted that some employer preferences (and, hence, factors determining applicant "marketability") have not been definitively shown to be productivity-related (e.g., Doeringer \& Piore, 1971; Thurow, 1975). For example, low marketability may be the result of various forms of discrimination (e.g., occupational crowding or statistical discrimination) rather than true productivity-related differences (Arrow, 1972; Spence, 1973).

Thus, it is not clear that all marketability-related characteristics (e.g., age, sex, prior experience) are associated with true differences in productivity, length of service, and other determinants of overall utility. Indeed, it is possible that pursuit of nontraditional applicants will sometimes lead to greater utility, because such individuals may be equally productive, but work for lower wages than conventional applicants (Doeringer \& Piore, 1971). In any event, because pursuit of nontraditional applicants appears to be a common adaptation to attraction difficulties, additional research is warranted in this area.

\section{Contingencies Affecting Choice of Strategy}

The three attraction strategies discussed in the preceding section are not perfect substitutes. They vary both in potential effectiveness (i.e., quality and quantity of applicants attracted) and potential costs (i.e., direct dollar outlays and threats to organizational productivity). 
Changes in recruitment practices, for example, are relatively low-cost strategies that are likely to have few consequences beyond the attitudes and behaviors of the employees attracted. However, their impact on attraction may also be limited, particularly in tight labor markets (Doeringer \& Piore, 1971). In contrast, changes in applicant pools and inducements are more extreme in the sense that they entail higher costs and/or greater risks (Wanous \& Colella, in press). However, these strategies are also likely to yield greater changes in attraction outcomes (Rynes, in press).

The three strategies, then, are not perfectly interchangeable. Given a perceived need to enhance attraction, which strategy will an organization choose? To some extent, the choice will depend on the organization's unique situation and idiosyncratic practices. Nevertheless, some general contingencies affecting these choices can be proposed. Four such factors, intended to be illustrative rather than all-inclusive, are discussed below.

\section{Labor Market Conditions}

The supply of available workers, relative to demand, determines the severity of an organization's attraction problem. As the magnitude, duration, or anticipated duration of shortages increase, organizations become increasingly willing to employ more costly attraction strategies. For example, evidence suggests that when shortages first develop, organizations typically respond by altering recruitment (Doeringer \& Piore, 1971). However, they move on to pool and inducement strategies as shortages deepen or persist (Kerr \& Fisher, 1950; Malm, 1955; Osterman, 1987). Thus:

P1: All else equal, in the initial stages of a labor shortage, recruitment strategies will be preferred over inducement or applicant pool strategies.

P2: The larger the imbalance between supply and demand, the greater the likelihood that inducement or nontraditional applicant strategies will be employed.

P3: The longer the expected duration of a labor shortage, the greater the tendency to use inducement or pool strategies. 


\section{Vacancy Characteristics}

Several vacancy characteristics are also likely to impact on choice of strategy. For example, vacancies at higher levels are believed to entail both greater potential value, and risk, to an organization. As such, changes in applicant pools are likely to be resisted due to the greater uncertainty involved in hiring individuals with unknown productivity characteristics. In contrast, inducement strategies may be considered more attractive because of the greater potential payoffs to attracting high-quality applicants. Thus:

P4: Nontraditional applicant pool strategies are less likely to be employed at higher position levels.

P5: The use of inducement strategies increases at higher position levels.

Attraction strategies may also depend on the degree to which vacancies are embedded in a career progression. Because strongly embedded positions are more visible to other employees, changes in inducements and/or applicant characteristics would be expected to have greater cost and productivity spillover to other positions (Doeringer \& Piore, 1971; Granovetter, 1986; Lewin, 1987). As such, embeddedness would be expected to favor conservative attraction strategies. Hence:

P6: Inducement and applicant pool strategies are less likely to be employed for jobs that are strongly embedded in an internal career progression.

The number of incumbents in a position may also affect attraction strategies. For example, inducement strategies are less expensive when they do not have to be applied to a large number

of peers. Applicant pool strategies may also be more feasible, in that it is less likely that a job with few incumbents will be strongly sex-, race-, or otherwise stereotyped (Kanter, 1977). Therefore, we predict:

P7: Organizations will be more likely to use inducement strategies when the number of present incumbents is small.

P8: Large numbers of incumbents will decrease the propensity to seek nontraditional applicants. 
Finally, the attractiveness of a vacancy is also likely to have an effect on strategic choices. For example, when vacancies are highly attractive relative to competitors, one would predict less need to employ extreme attraction strategies. Additionally, the content of recruitment messages may also change with differences in vacancy attractiveness. For example, although most employers appear to avoid realistic recruitment due to anticipated negative effects on attraction (Schneider, 1976; Stoops, 1984), this tendency is likely to be considerably abated when one's vacancies are more attractive than competitors'. Thus:

P9: The higher a vacancy's attractiveness relative to competitors, the less will be the need to turn to inducement or nontraditional applicant strategies.

P10: As vacancies increase in attractiveness, recruitment messages are likely to become increasingly realistic.

\section{Organizational Constraints}

A variety of organizational constraints also impinge on attraction strategies. We focus here on three factors: rigidity of skill requirements; ability to pay, and strength of internal labor market norms.

Organizations with very specific skill requirements may be limited to hiring from certain applicant pools, particularly if the needed skills cannot be acquired internally in a reasonable period of time and jobs cannot be redesigned to reduce skill requirements. In such situations, changing applicant pools is not a viable option. On the other hand, inducement strategies may be more readily employed with rigid skill requirements, particularly when the skill shortage is general to other organizations as well. Thus:

P11: Organizations are less likely to employ applicant pool strategies when skill requirements are inflexible.

P12: With rigid skill requirements, recruitment strategies are more likely to be employed than inducement strategies when skill shortages are specific to the organization. However, as skill shortages become more general, inducement strategies are increasingly likely to be employed (largely due to a lack of other alternatives). 
A second constraint is the organization's ability to pay for changes in inducements. Such changes may entail substantial direct costs, particularly if there are many vacancies and/or enhanced inducements cannot be restricted to new hires. Thus, inducement strategies are less likely to be employed by organizations with low ability to pay. On the other hand, nontraditional applicant pools may be explicitly sought for their lower presumed costs (e.g., Lewin, 1987; Osterman, 1987). Thus:

P13: Organizations with low ability to pay are less likely to use inducement strategies, but may be more inclined to consider nontraditional applicant pools.

Finally, the nature of an organization's culture and values may also influence the choice of attraction strategies. For example, to the extent that the culture emphasizes internal pay equity and "lifetime" careers, one would expect to find more limited use of extreme attraction strategies (e.g., changing applicant characteristics or enhancing inducements to "outsiders"). Thus:

P14: Organizations with internally oriented cultures and values will be less inclined to use either inducement or nontraditional pool strategies.

\section{Phase of the Attraction Process}

In order to fill vacancies, organizations must first "attract" individuals to submit an application, to undergo various screening procedures, and to accept job offers. A shortage of willing or qualified applicants at any one of these stages creates a need to modify attraction strategies. The appropriate modification may be a function of the stage where the shortage occurs.

For example, recruitment activities may be effective in encouraging initial applications. However, evidence suggests that recruitment practices become less important as candidates move closer to making a job choice (Rynes, in press; Taylor \& Bergmann, 1987). Therefore, shortages occurring later in the process (e.g., low job acceptance ratios) may be ineffectually addressed by recruitment strategies. Thus: 
P15: Attraction difficulties at early stages are most likely to be adequately dealt with through recruitment; difficulties at later stages are likely to require more extreme strategies.

\section{Interrelationships among Alternative Strategies}

Although various contingencies may lead organizations to focus primarily on one strategy, we do not propose that organizations are restricted to using a single approach. In fact, interdependencies between the alternatives make reliance on a single strategy unlikely. A complete discussion of all possible interdependencies is beyond the scope of this paper. However, in the following section we discuss selected situations where decisions and outcomes involving one attraction strategy would appear to be integrally related to choices concerning other strategies.

\section{Applicant Pools and Inducements}

Efficiency wage and segmented market theories suggest that both the quantity and quality of availabe workers are functions of the level of inducements offered (e.g., Thurow, 1975; Weiss, 1980; Yellen, 1984). Simply put, "better" applicants are expected to be attracted to, and to remain in, "better" vacancies. Thus, all else equal, organizations that seek highly marketable applicants must either enhance inducements or accept lower levels of attraction success (e.g., insufficient job acceptances or acceptances from individuals at the bottom of the pool). Therefore, we propose that:

P 16: Applicant pool choices are determined, at least in part, by the level of inducements offered. Conversely, choice of particular pools may dictate changes in inducements.

Decisions about applicant pools also appear to interact with the type of inducements offered. For example, employer-subsidized childcare has been used to attract parents of young children, educational benefits to attract college-oriented youth, and part-time or flexible schedules to attract students, parents, and retirees (e.g., Merrill, 1987; Tannen, 1987). Thus, organizations 
wishing to target a specific applicant pool may find tailoring inducements to that pool a costeffective strategy:

$P$ 17: Inducement strategies, particularly those involving optional benefits or flexible scheduling, may be designed to complement applicant pool characteristics. Conversely, applicant pool choices are at least partially constrained by the ability to modify particular inducements.

\section{Applicant Pools and Recruitment}

Decisions to seek nontraditional applicants may bring about changes in recruitment practices as well. Recruitment sources, representatives, and messages seem particularly likely to be affected.

Because different kinds of applicants use different sources (Schwab, 1982; Taylor \& Schmidt, 1983), applicant pool and recruitment source decisions are closely intertwined. However, sources are chosen for a variety of reasons other than targeting a particular pool (e.g., cost, prescreening services), and a given pool can almost always be accessed via multiple sources. Thus, although a decision to target nontraditional applicants does not completely dictate the choice of source(s), there would appear to be considerable interdependencies between these two decisions. For example, we hypothesize that:

P18: Decisions to target nontraditional applicants will be accompanied by shifts in recruitment sources. In particular, walk-ins and employee referrals are likely to be used less often, as these sources are most likely to produce applicants similar to current employees.

The choice of organizational representatives may also be affected by decisions to target nontraditional applicants. Although previous research suggests that representatives do not have much effect on actual job choices, there is limited evidence that applicants prefer representatives that are largely similar to themselves, although somewhat higher in status (Rynes, in press). Also, although the issue has not received prior research attention, it is possible that perceived similarity is more important for attracting "nontraditional" than conventional applicants. Thus, we speculate that: 
P19: Decisions to target nontraditional applicants are frequently accompanied by shifts to "nontraditional" organizational representatives (e.g., recruiters, employees featured in recruiting brochures) as well.

Finally, decisions to pursue nontraditional applicants may also lead to modifications of recruitment messages. For example, focusing on characteristics that are highly salient to applicants will probably have a greater impact (either positive or negative) on attraction than emphasizing less important factors.

Although we have only limited information about the salience of various job characteristics to different kinds of applicants, there is some evidence that relative importance is associated with both individual (e.g., age, sex, education) and occupational differences (e.g., Goldthorpe, Lockwood, Bechhofer, \& Platt, 1969; Jurgensen, 1978; Rynes et al., 1983). To the extent that such differences can be reliably determined, message content can be effectively tailored to any given applicant pool (e.g., Krett \& Stright, 1985). Thus, we expect that:

P20: Recruitment messages reflect the perceived salience of various attributes to the desired applicant pool.

Inducements and Recruitment

Both economic and psychological research suggest that applicants typically have little information about the specific characteristics of vacancies and organizations (e.g., Schwab, et al., 1987). Consequently, organizations that modify inducements cannot assume that potential applicants will automatically be aware of those changes. Thus:

P21: Changes in inducements will affect attraction only to the extent that such changes are communicated effectively through the recruitment process.

For example, the success of recent Armed Services recruitment and reenlistment programs (Lakhani, 1988; Tannen, 1987) may be due in part to the extensive national advertising campaigns that accompanied their introduction. Moreover, the inducements offered in both these cases were tangible and easy to verify. Where inducements are intangible (e.g., responsibility, challenge), credibility becomes an issue and effective communication is more difficult. Hence: 


\section{P 22: Strategies to enhance nonverifiable inducements are more dependent on effective recruitment practices than are strategies involving verifiable inducements.}

To this point, we have focused on the strategic choices available to organizations faced with attraction difficulties. In subsequent sections, we discuss various consequences of those choices.

\section{Attraction Outcomes}

In this section, we focus only on attraction outcomes per se; that is, outcomes that occur up to the point of job acceptance or rejection (Figure 1). Potential post-hire consequences are discussed in subsequent sections.

\section{Quantitative versus Qualitative Outcomes}

Relatively little is known about the number of applicants attracted by different strategies. This is due primarily to the tendency of previous researchers to use the applicant, rather than the organization, as the unit of analysis. However, there are both conceptual (e.g., Thurow, 1975) and empirical (e.g., Rynes \& Boudreau, 1986) reasons to believe that most vacancies are

eventually filled with someone. If so, the most interesting questions involve not the numbers, but the characteristics, of those attracted.

Unfortunately, even less is known about the quality of those attracted via various strategies than the quantity. For example, realistic preview researchers have focused on job acceptance rates while ignoring the qualifications of those who accept versus reject job offers. As such, it is possible that the most marketable applicants are the ones "scared off" by realistic previews, particularly when vacancies are relatively unattractive.

Admittedly, assessing applicant quality is more difficult than recording simple headcounts. Although some productivity-related characteristics are directly observable (e.g., possession of particular skills), others can only be inferred via imperfect signals (e.g., grade point averages, test scores, school quality; Spence, 1973; Thurow, 1975). Still, three types of qualitative 
comparisons would appear to be particularly desirable in future research --comparisons (a) with those who apply to or accept offers from close competitors, (b) between individuals from particular sources (e.g., top-tier schools) who do, or do not, accept one's interviews or job offers, and (c) between characteristics of acquired employees and a priori selection standards or targets.

\section{Attitudinal versus Behavioral Outcomes}

Attraction also has both attitudinal and behavioral consequences. However, attitudinal outcomes have been better represented than behavioral ones, particularly in the organizational behavior and psychology literatures. For example, the vast majority of recruitment research has focused on applicant attitudes toward recruiters, jobs, and probable willingness to accept offers (e.g., Harris \& Fink, 1987). Only a few studies, primarily in economics, have focused on application and acceptance behaviors (e.g., Hanssens \& Levien, 1983; Lakhani, 1988).

Although attitudes may be important for public relations purposes, behaviors (e.g., actual applications and acceptances) are more critical for filling vacancies. It has been argued that intention to engage in a behavior is closely related to the actual behavior (e.g., Fishbein \& Ajzen, 1975). However, evidence on this issue, particularly with regard to attraction attitudes and behaviors, is scarce. After all, applicants may express a high degree of willingness to accept six or seven offers, but can accept only one. Similarly, applicants can "like" eight or nine recnuiters, but choose a tenth offer with a disliked recruiter. Because nearly all research has been conducted between- rather than within-applicants, any presumed relationship between attitudes and behaviors is tenuous at best.

\section{Temporal Dimensions}

Prior research has been decidedly uneven with respect to outcomes at various stages of the attraction process. Generally speaking, outcomes from initial interviews have received far more attention than either prior or subsequent outcomes (see also Taylor \& Bergmann, 1987). For 
example, outcomes at the job application stage have been dramatically understudied (Kilduff, 1988) despite their crucial importance to an organization's ability to generate job acceptances. As such, we know very little about the factors that cause job seekers to apply for some vacancies, but not others (e.g., social contacts and influences, perceived organizational image; e.g., Granovetter, 1974; Kilduff, 1988; Kolenko \& Taylor, 1984). Similarly, we know relatively little about the factors that cause applicants to choose one altemative above all others, or to reject an offer in hand despite an absence of alternative offers (Schwab, et al., 1987).

\section{Attraction and Other Human Resource Practices}

Attraction strategies are related to other HR practices in at least three ways (Figure 1). First, as discussed in previous sections, the viability of particular attraction strategies is partially determined by current HR practices. For example, changes in monetary inducements may be less feasible in organizations where compensation practices place a strong emphasis on internal equity (Doeringer \& Piore, 1971).

Second, changes in attraction strategies often cannot be successfully operationalized without simultaneous changes in other HR practices. For example, shifts to nontraditional applicant pools may be resisted unless accompanied by more rigorous selection practices to counteract the increased uncertainty of hiring "unknown entities" (e.g., Doeringer \& Piore, 1971).

Nontraditional pool strategies may also require changes in job design. For example, law firms faced with dwindling supplies of top-tier law graduates accompanied the shift to second-tier applicants with the creation of less challenging entry-level positions that were segmented from the partnership career path (Lewin, 1987). Conversely, job enlargement has sometimes been used to attract a higher qualified, more flexible workforce (e.g., Lawler, 1986).

Third, attraction practices (and their resultant outcomes) are also likely to affect post-hire HR practices. For example, nontraditional applicant pools may be easier or less expensive to attract, but may require additional socialization and training investments (e.g., Kanter, 1977). 
Alternatively, enhanced inducement strategies are likely to ease most management tasks (e.g., orientation, training, performance management), both by attracting higher-quality applicants and by motivating incumbents to exert greater effort (as job loss becomes more costly; e.g., Weiss, 1980; Yellen, 1984).

The preceding examples represent a partial list of the ways in which attraction strategies and outcomes have been hypothesized to interact with other HR practices. The following section discusses how they are believed to influence post-hire organizational outcomes as well.

\section{Applicant Attraction and Post-Hire Consequences}

To date, relationships between attraction strategies and post-hire outcomes have been addressed primarily in the recruitment literature, particularly the recruitment source and RJP literatures. The latter in particular has called attention to potentially negative relationships between attraction strategies (e.g., overselling vacancies) and post-hire outcomes (e.g., employee satisfaction and retention; Premack \& Wanous, 1985). However, many other potentially important relationships, both positive and negative, have been largely ignored. Selected examples are offered below.

A whole array of interesting post-hire issues is raised by the prospect of targeting nontraditional applicant pools. For example, attraction of nontraditional applicants may increase long-term organizational adapability and performance (Schneider, 1987). On the other hand, recruiting new types is frequently resisted by organizational insiders and can result in negative as well as positive outcomes, particularly in the shorter term (e.g., Granovetter, 1986; Sutton \& Louis, 1987). For example, Granovetter (1986) argues that the hiring of nontraditional applicants (e.g., blacks instead of whites, fresh college graduates instead of "insiders") may result in the refusal of current employees to engage in the kinds of socialization and training

behaviors necessary for new employees to be successful performers. Additionally, the hiring of nontraditional employees can result in reduced solidarity among workers, the emergence of 
separate "enclaves" of demographically distinct workers, and the re-drawing of conventional career lines and intemal labor market patterns (e.g., Edwards, Gordon \& Reich, 1975; Kanter, 1977). Finally, recruiting nontraditional applicants can cause current employees to see their own jobs in a different light, as nontraditional applicants bring new information about comparative conditions in other organizations or industries (Sutton \& Louis, 1987).

Employment inducements are also believed to affect post-hire outcomes, particularly retention and performance. For example, inducements that enhance attraction would also be expected to increase retention (e.g., Lakhani, 1988; Tannen, 1987). Also, as mentioned previously, presumed positive relationships between inducement levels, employee quality, and motivation would be expected to result in higher productivity in high-inducement organizations.

Relationships between recruitment timing and post-hire outcomes also merit future attention. For example, it has been hypothesized that early pursuit of applicants may result in larger and better qualified applicant pools, as well as higher job acceptance rates (e.g., Schwab, et al., 1987). To date, however, these hypotheses have not been examined. Similarly, the effects of organizationally-imposed deadlines to accept early offers have also escaped scrutiny. However. prior discussions of the dissonance resolution processes surrounding job acceptance suggest that the timing of recruitment contacts, offers, and offer deadlines may have a nontrivial impact on new employee adjustment (e.g., Janis \& Mann, 1977; Soelberg, 1967).

\section{Implications for Future Research}

The present perspective on applicant attraction holds a number of important implications for future research. These are summarized in terms of suggestions for organization-oriented research, applicant-oriented research, and applicant/organization interactions.

Organization-Oriented Research. One way in which attraction research could be made more relevant to organizations is to conduct more research from the organization's perspective. Three 
general kinds of research -- field experiments, field surveys, and basic descriptive research -would appear to be particularly useful in this regard.

Field experiments have already been used to study RJPs and, at least in the Armed Services, the effects of changes in employment inducements. However, field experiments could additionally be designed to analyze the effects of changes in recruiter selection or training practices, recruitment timing or sources, or targeted applicant pools. In each case, attempts should be made to assess as many relevant outcomes as possible (e.g., pre- and post-hire. quantitative and qualitative, multiple stages) so that results reflect overall utility as closely as possible (Boudreau \& Rynes, 1985).

Field surveys might also play an important role in bringing more of an organizational orientation to attraction research. For example, in large organizations, survey designs could be used to model attraction as a function of business unit recruitment practices and expenditures, relative wage and benefit levels, market conditions, and so on (e.g., see Hanssens \& Levien, 1983). In this way, the cost-benefit relationships associated with various attraction practices might be determined, controlling for variations in market conditions. Similar studies could also be designed across organizations within a given industry.

There is also a call for basic descriptive work on how attraction strategies actually emerge in organizations. For example, little research exists conceming the following aspects of the present model: (1) what conditions (and at what level of severity) trigger searches for new attraction strategies; (2) the extent to which attraction strategies are hierarchically ordered (e.g.. recruitment first, targeted pools second, inducements third), versus contingency-based, (3) whether changes in certain attraction strategies (e.g., applicant targets) invariably invoke consideration of other strategies (e.g., inducement levels), and (4) who are the major players in the decision making process under varying conditions (e.g., under what conditions does input from line management increase or decrease?). Insights into such questions might be gained by 
studying differences in attraction strategies between low-paying versus high-paying organizations, organizations in growth versus decline stages, or within-organization differences in attraction strategies for high-versus low-demand occupations.

Applicant-Oriented Research. With a few modifications, results from applicant-oriented research could also be made more relevant to organizations. One such modification would be to ensure that future studies of recruitment practices include information about pre-hire as well as post-hire outcomes, and dropouts as well as acceptees (see also Boudreau \& Rynes, 1985). Until the effects of employer selection, employee self-selection, and post-hire events are are disentangled in recruitment research, no conclusions can be drawn about the overall utility of various recruitment strategies, or of the dynamics involved in producing observed post-hire effects. Thus, longitudinal research combining pre- and post-hire outcomes (both qualitative and quantitative) would be extremely valuable.

A second contribution would be to study applicant decisions at more phases of the organizational choice process. As noted earlier, virtually all recruitment research has been conducted at the campus interview stage, when a variety of applicant self-selection (and organizational selection) decisions have already been made.

In addition to examining different phases of the process, attention should be paid to selecting the appropriate dependent variable(s) for each phase. For example, most studies of the campus interview use willingness to accept the job as a dependent variable (e.g., Harris \& Fink. 1987; Rynes \& Miller, 1983). In fact, however, the primary decision at this stage is whether or not to continue in the recruitment process (e.g., whether to accept a site visit). In contrast, job acceptance decisions are typically made only after acquiring considerably more information. both about the job of interest and about competing alternatives.

Third, applicant-oriented research has been conducted almost exclusively where applicants are plentiful and easily accessible to researchers; i.e., on college campuses. This practice has 
resulted in serious restriction of range in terms of the types of job seekers, vacancies, and labor markets studied (Rynes, et al., 1980; Wanous \& Colella, in press). For example, we know very little about how job seekers behave in markets without centralized intermediaries (e.g., the college placement office), or how currently-employed individuals find new jobs (Schwab, et al., 1987). Homogeneous sampling has also inhibited our ability to detect potential interactions between applicant characteristics and various attraction practices.

Fourth, previous applicant-oriented research has been based almost exclusively on applicant perceptions. As such, we rarely have information about "true" levels of studied variables (e.g., recruiter competence, employment inducements) or the accuracy of applicants' perceptions (see Wanous, 1977). Given the documented uncertainty surrounding most job choice decisions (e.g.. Reynolds, 1951; Schwab et al., 1987), common method variance and a variety of cognitive and perceptual biases represent serious threats to the internal validity of such research (e.g., Janis \& Mann, 1977; Schwab et al., 1987; Soelberg, 1967). In short, there is a need to supplement applicant perceptual data in future research, either with objective data or with perceptual data from other sources.

Finally, the tendency to study only one (or at most two) attraction-related strategies at a time has probably contributed to serious omitted variable bias in terms of what we think we know about attraction (James, Mulaik \& Brett, 1982). For example, most prior research suggests that observed recruiter effect sizes are smaller when employment inducements are taken into account than when they are not (e.g., Powell, 1984; Rynes \& Miller, 1983: Taylor \& Bergmann, 1987). This suggests that even when researchers are interested primarily in one attraction strategy (e.g., recruitment timing), they should be careful to document other potentially relevant variables (e.g., level of inducements, occupational and geographical labor market conditions). At the very least, such practices would contribute to a more efficient search for possible moderators via future meta-analyses. 
Applicant/Organization Interactions. Research is also needed that explicitly examines interactions between applicants' and organizations' behaviors and decisions. Two key issues involve (1) the extent to which organizations and applicants "sort" themselves into hierarchies (and, if so, on what dimensions), and (2) how information is communicated from one party to the other.

If (as economists and sociologists argue) general hierarchies of job and applicant attractiveness exist, at least two additional questions are raised. One is whether, or under what conditions, applicants or organizations self-select out of the attraction process because of beliefs that they are in a "lower tier" than the opposing party. For example, second tier employers may attempt to attract students from top tier universities, rationalizing that (1) some students will be successfully attracted because of lower relative marketability or poor information about altematives, and (2) even if such attempts fail, they can always recruit later at lower-ranked schools (Thurow, 1975). On the other hand, these organizations may choose to avoid top tier sources if costs of recruiting exceed benefits (e.g., if acceptance rates are extremely low, or if only the least desirable candidates can be attracted).

On the applicant side, expectancy theory and some efficiency wage theorists argue that applicants self-select out of the application process when confronted with "good" vacancies which they feel underqualified to fill (Schwab, et al., 1987; Weiss, 1980). However, others suggest that applicants, like employers, aim as high as they can, hoping top-tier employers will (perhaps mistakenly) accept them (e.g., Thurow, 1975). Still others suggest that there may be considerable individual differences in self-selection strategies (e.g., Rynes \& Lawler, 1983).

A second sorting question concems whether or not the timing of organizational and applicant search activities are correlated with one's position in the hierarchy. As mentioned earlier, it has been speculated but not demonstrated that the most desirable employers and 
applicants match up early, with lower-tier matches occurring in subsequent periods (e.g., Schwab, et al., 1987; Thurow, 1975).

With regard to pre-hire communications between applicants and organizations, at least two questions merit future attention. One concerns the signalling that occurs between applicants and organizations in the absence of perfect information (e.g., Rynes \& Miller, 1983; Spence, 1973). Given imperfect information, interesting questions exist about the inferences drawn from observable characteristics (organization's product, applicant's GPA) to important "unknowns" (e.g., organizational growth potential, applicant motivation).

Informational uncertainties also raise questions about manipulating the order of information presentation, as well as the techniques used to inform the opposing party about unverifiable attributes (e.g., applicant motivation, organizational career prospects). Because such issues are generally subject to substantial organizational and applicant control, they would appear to be fruitful areas for future research.

\section{Conclusion}

Prior research on attraction is dispersed across a variety of literatures, each of which has developed its own unique perspective of the attraction process. For example, industrial psychologists have focused on recruitment practices and applicant attitudes; economists on employment inducements and applicant behaviors, and sociologists on social aspects of job search and early socialization.

An integration of these perspectives is particularly desirable in light of widespread anticipated labor shortages (Johnston, 1987). These shortages will force more and more organizations to shift from "scripted" attraction behaviors to conscious strategic deliberation. The present paper provides a tentative framework for organizational decision makers confronted with attraction challenges, as well as for researchers who wish to increase our understanding of the entire attraction process. 


\section{References}

Arrow, K. J. (1972) Models of discrimination. In A. H. Pascal Ed.), Racial Discrimination in Economic Life. Lexington, MA.: Lexington Books.

Arvey, R., Gordon, M., Massengill, D., \& Mussio, S. (1975). Differential dropout rates of minority and majority job candidates due to time lags between selection procedures. Personnel Psychology, 38, 175-180.

Bernstein, A. (1987) Dispelling the myths about a higher minimum wage. Business Week, Oct. 19 , p. 146.

Boudreau, J. W., \& Rynes, S. L. (1985) Role of recruitment in staffing utility analysis. Journal of Applied Psychology, 70, 354-366.

Breaugh, J. A. (1981) Relationships between recruiting sources and employee performance, absenteeism, and work attitudes. Academy of Management Journal, 24, 142, 147-148.

Doeringer, P.B. and Piore, M. (1971) Internal labor markets and manpower analysis. Lexington, MA.: Lexington Books, Inc.

Finney, M.I. (1989). The ASPA labor shortage survey. Personnel Administrator, 34, \#2, 35-42.

Fishbein, M. \& Ajzen, I. (1975). Belief, attitude, intention and behavior: An introduction to theory and research. Reading, MA.: Addison-Wesley.

Fisher, C.D. (1986). Organizational socialization: An integrative review. In K.M. Rowland and G.R. Ferris (Eds.), Research in Personnel and Human Resources Management, Vol. 4, 101-146. Boston: Allyn \& Bacon.

Fisher, C.D., Ilgen, D.R. \& Hoyer, W.D. (1979). Source credibility, information favorability. and job offer acceptance. Academy of Management Journal. 22. 94-103.

Goldthorpe, J.H., Lockwood, D., Bechhofer, F., and Platt, J. (1969). The affluent worker in the class structure. Cambridge: Cambridge University Press.

Gordon, D.M., Edwards, R. \& Reich, M. (1982). Segmented work, divided workers: The 
historical tranformation of labor in the United States. Cambridge: Cambridge University Press.

Granovetter, M.S. (1974) Getting a job: A study of contacts and careers. Cambridge, MA.: Harvard University Press.

Granovetter, M.S. (1986) Labor mobility, intemal markets, and job matching: A comparison of the sociological and economicapproaches. In R.V. Robinson (Ed.), Research in Social Stratification and Mobility, Vol. 5, 3-39.

Guion, R. M. (1976) Recruiting, selection, and job placement. In M.D. Dunnette (Ed.), Handbook of industrial and organizational psychology, 777-828. Chicago, Rand-McNally. Hanigan, M. (1987) Campus recruiters upgrade their pitch. Personnel Administrator, 32, 55-58. Hanssens, D. M., \& Levien, H. A. (1983) An econometric study of recruitment marketing in the U. S. Navy. Management Science, 29, 1167-1184.

Harris, M. M., \& Fink, L. S. (1987) A field study of employment opportunities: Does the recruiter make a difference? Personnel Psychology, 40, 765-784.

James, L. R., Mulaik, S. A., \& Brett, J. M. (1982) Causal analysis: Assumptions, models, and data. Beverly Hills: Sage Publications.

Janis, I.L. \& Mann, L. (1977) Decision making: A psychological analysis of conflict, choice and commitment. New York: The Free Press.

Johnston, W. B. (1987) Workforce 2000: Work and workers for the 21st century. Indianapolis: Hudson Institute.

Jurgensen, C. E. (1978) Job preferences (What makes a job good or bad?) Joumal of Applied Psychology, 63, 267-276.

Kanter, R.M. (1977) Men and women of the corporation. New York: Basic Books.

Kerr, C., \& Fisher, L.H. (1950) Effect of environment andadministration on job evaluation. Harvard Business Review, 77-96. 
Kilduff, M. J. (1988) Decision making in context: Social and personality correlates of choices of organizations. Ithaca, NY.: Unpublished doctoral dissertation, Comell University.

Klein, H.J. (1989) An integrated control theory model of work motivation. Academy of Management Review, 14, 150-172.

Kolenko, T.A. \& Taylor, M.S. (1984) Organizational image: Dimensionality and relationships to job search attitudes and behaviors. Working paper, University of Wisconsin.

Krett, K., \& Stright, J. F. (1985) Using market research as a recruitment strategy. Personnel, $62,32-36$.

Lakhani, H. (1988) The effect of pay and retention bonuses on quit rates in the U. S. Army. Industrial and Labor Relations Review, 41, 430-438.

Lawler, E.E. III. (1971) Pay and organizational effectiveness: A psychological view. New York: McGraw-Hill.

Lawler, E.E. III (1986). High involvement management. San Francisco: Jossey-Bass.

Lewin, T. (1987). Law firms add second tier. New York Times, March 11, 1987.

Malm, F. T. (1955) Hiring procedures and selection standards in the San Francisco Bay area. Industrial and Labor Relations Review, 8, 231-252.

Merrill, P. (1987) Sign of the times. Personnel Administrator, 32, 62-65.

Olian, J.D. \& Blackburn, R.S. (1983) An information processing approach to perceptions of organizations within the job search framework. Working paper, University of Maryland.

Osterman, P. (1987) Choice of employment systems in internal labor markets. Industrial Relations, 26, 46-67.

Powell, G. N. (1984) Effects of job attributes and recruiting practices on applicant decisions: A comparison. Personnel Psychology, 37, 721-732.

Premack, S. L., \& Wanous, J. P. (1985) A meta-analysis of realistic job preview experiments. Journal of Applied Psychology, 70, 706-719. 
Reynolds, L. G. (1951) The structure of labor markets. New York: Harper \& Bros.

Rottenberg, S. (1956) On choice in labor markets. Industrial and Labor Relations Review, 9, 183-199.

Rynes, S. L. (In press). Recruitment, job choice, and post-hire consequences: A call for new research directions. In M. D. Dunnette (Ed.), Handbook of Industrial and Organizational Psychology, 2nd ed. Palo Alto: Consulting Psychologists' Press, Inc.

Rynes, S. L., \& Boudreau, J. W. (1986) College recruiting in large organizations: Practice, evaluation, and research implications. Personnel Psychology, 39, 729-758.

Rynes, S. L., Heneman, H. G. III, \& Schwab, D. P. (1980) Individual reactions to organizational recruiting: A review. Personnel Psychology, 33, 529-542.

Rynes, S. L. \& Lawler, J. (1983) A policy-capturing investigation of the role of expectancies in decisions to pursue job altematives. Journal of Applied Psychology, 68, 620-631.

Rynes, S. L., \& Miller, H. E. (1983) Recruiter and job influences on candidates for employment. Journal of Applied Psychology, 68, 147-154.

Rynes, S. L., Schwab, D. P., \& Heneman, H. G. III (1983) The role of pay and market pay variability in job application decisions. Organizational Behavior and Human Performance, 31, 353-364.

Schneider, B. (1976) Staffing organizations. Santa Monica: Goodyear.

Schneider, B. (1987) The people make the place. Personnel Psychology, 40, 437-454.

Schwab, D. P. (1982) Recruiting and organizational participation. In K. Rowland and G. Ferris Eds.), Personnel management. Boston: Allyn \& Bacon, 103-128.

Schwab, D. P., Rynes, S. L., \& Aldag, R. J. (1987) Theories and research on job search and choice. In K. Rowland \& G. Ferris (Eds.), Research in personnel and human resource management, Vol. 5, 129-166. Greenwich: JAI Press.

Smith, A. (1963) The wealth of nations (vol. 1). Homewood, Il.: Irwin. 
Soelberg, P. O. (1967) Unprogrammed decision making. Industrial Management Review, 8, 19-29.

Spence, M. (1973) Job market signalling. Quarterly Journal of Economics, 87, 355-374.

Stoops, R. (1984) Reader survey supports marketing approach to recruitment. Personnel Joumal, 63, 22-24.

Sutton, R.I. \& Louis, M.R. (1987) How selecting and socializing newcomers influences insiders. Human Resource Management, 26, 347-361.

Tannen, M. B. (1987) Is the Army college fund meeting its objectives? Industrial and Labor Relations Review, 41, 50-62.

Taylor, M. S., \& Bergmann, T. J. (1987) Organizational recruitment activities and applicants' reactions at different stages of the recruitment process. Personnel Psychology, 40, 261-285.

Taylor, M.S., \& Schmidt, D.W. (1983) A process-oriented investigation of recruitment source effectiveness. Personnel Psychology, 36, 343-354.

Thurow, L. (1975) Generating inequality. New York: Basic Books.

Ullman, J. C. (1966) Employee referrals: Prime tool for recruiting workers. Personnel, 43, 30-35.

Wanous, J. P. (1977) Organizational entry: Newcomers moving from outside to inside. Psychological Bulletin, 84(4), 601-618.

Wanous, J. P. (1980) Organizational entry: Recruitment, selection, and socialization of newcomers. Reading, Ma.: Addison-Wesley.

Wanous, J. P., \& Colella, A. (In press). Organizational entry research: Current status and future directions. Forthcoming in K. Rowland \& G. Ferris (Eds.), Research in Personnel and Human Resources Management, Vol. 8. 
Weiss, A. (1980) Job queues and layoffs in labor markets with flexible wages. Journal of Political Economy, 88, 526-538.

Yellen, J.L. (1984) Efficiency wage models of unemployment, American Economic Review, 74, 200-205. 


\section{Footnotes}

1. Assessments of job attractiveness are admittedly subject to individual differences in tastes and preferences (e.g., Smith, 1963), as well as to characteristics of occupational labor markets (e.g., Rynes, et al., 1983). However, there appear to be some job characteristics that are generally preferred by most applicants (e.g., high pay and security, low physical risk;

Rottenberg, 1956), and some organizations that are generally preferred over others (e.g., Kolenko \& Taylor, 1984; Olian \& Blackburn, 1982). Moreover, efficiency wage and segmented market theories explicitly assume that hierarchies of both job, and applicant, "goodness" exist and are generally identifiable. As such, vacancy attractiveness appears to be at least roughly determinable (although rarely investigated empirically).

Similar arguments apply to general assessments of applicant quality (e.g., Arrow, 1972; Spence, 1973; Thurow, 1975). 


\section{Authors' Notes}

This research was carried out with support from the U.S. Army Research Institute, Contract SRFC-MDA903-87-K-0001. The views, opinions, and/or findings contained in this articles are those of the authors and should not be construed as official Department of the Army policy.

The authors wish to thank three anonymous reviewers for helpful comments on an earlier version of this manuscript. 


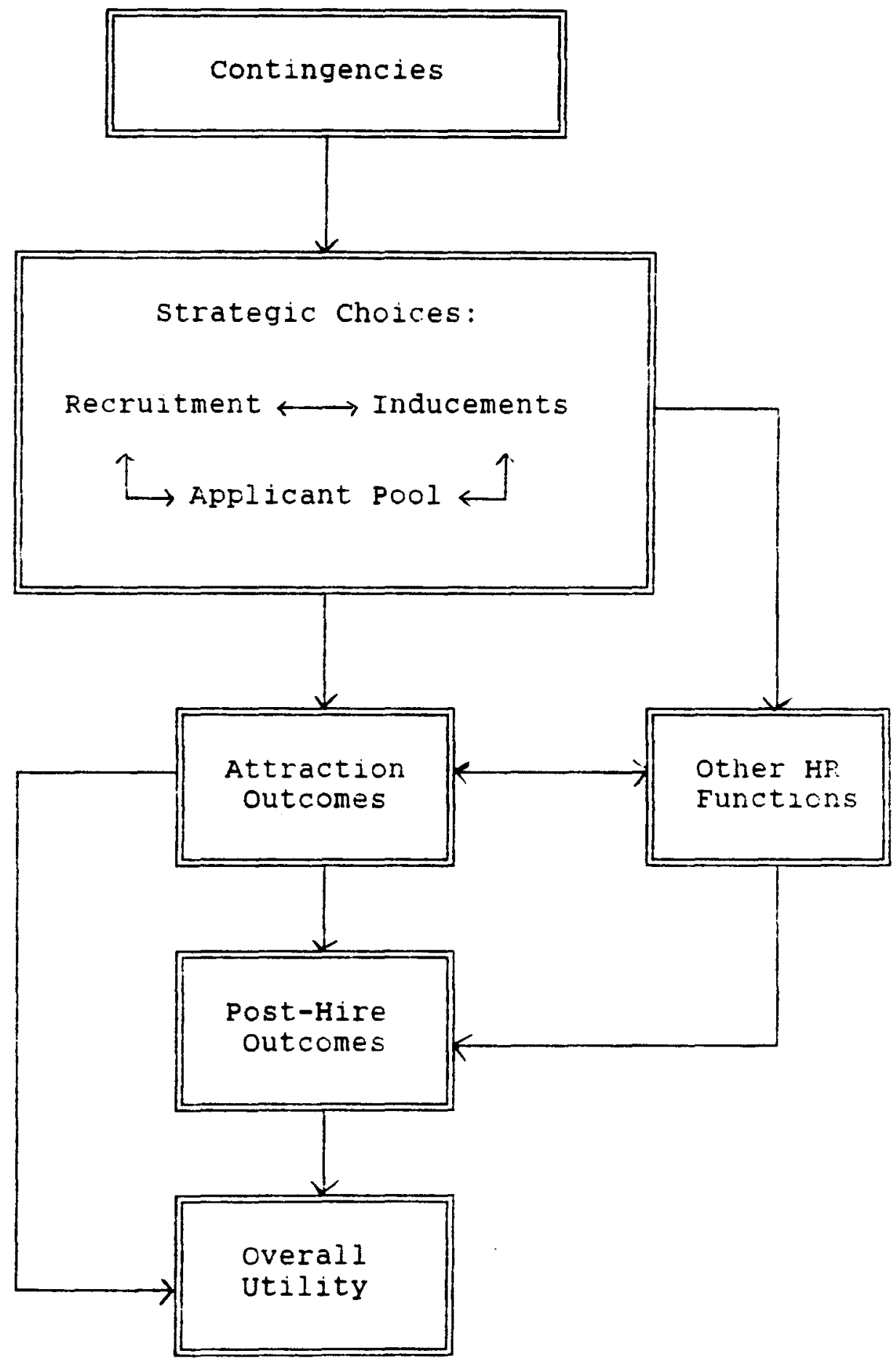

Eigure 1. Model of the attraction process. 